\title{
PEMBACAAN NOMOR SAMPEL DALAM REFURBISHING ALAT LOW BACKGROUND COUNTER-LBC TENNELEC TYPE LB5100 SERIES ॥
}

\author{
JOKO SUMANTO \\ Pusat Rekayasa Perangkat Nuklir-BATAN \\ Kawasan Puspiptek Gd.71 Serpong-Tangerang 15310 \\ Email: joko_prpn@yahoo.com
}

\begin{abstract}
Abstrak
PEMBACAAN NOMOR SAMPLE DALAM REFURBISHING ALAT LBC TENNELEC TYPE LB5100 SERIES II. Telah dirancang dan dibuat interface pembacaan nomor sample secara otomatis dengan komputer melalui komunikasi serial USB dalam rangka refurbishing alat LBC TENNELEC type LB5100. Refurbishing dilakukan dengan cara memanfaatkan bagian mekanik dari instrumen dan mengganti bagian elektronik yang kadaluwarsa dengan berbasis komputer pribadi-PC. Pada alat ini, sample yang diukur cukup banyak sehingga perlu dilakukan secara otomatis. Setiap sample telah ditandai dengan lobang-lobang yang disusun tertentu yang mengindikasikan nomor sample, group, dan send stack reader. Pada bagian mekanik diletakkan beberapa sensor photo transistor sesuai kedudukan sample. Sensor dihubungkan dengan jalur data dan dikirim ke komputer melalui komunikasi serial USB. Alat tersebut mampu mengukur 150 sampel dan 10 group. Hasil pengujian telah sesuai yang diharapkan.
\end{abstract}

Kata kunci : Refurbishing, LBC.

\begin{abstract}
SAMPLE NUMBER IN READING DEVICE LBC TENNELEC REFURBISHING LB5100 TYPE SERIES II. Has been designed and built the reading interface sample numbers automatically through a computer via a USB serial communication in the context of refurbishing equipment TENNELEC LBC type LB5100. Refurbishing is done by using the mechanics of the instrument and replace the expired electronic parts with a personal computer-based PCs. In this instrument, which measured sample enough so that needs to be done automatically. Each sample was marked with holes arranged to indicate a specific sample number, group, and send stack reader. Mechanical parts placed on a photo transistor sensor according to the position of samples. Sensors connected to the data lines and sent to a computer via a USB serial communications. Tool capable of measuring 150 samples and 10 groups. Test results have been as expected.
\end{abstract}

Keywords : Refurbishing, LBC 


\section{PENDAHULUAN}

Kegiatan refurbishing instrument adalah suatu usaha untuk memperpanjang umur pakai dari instrument berharga mahal, dalam rangka kemandirian dan penghematan devisa negara, dengan cara memanfaatkan bagian mekanik dari instrument dan mengganti bagian elektronik yang kadaluwarsa/rusak. Pada saat ini di BATAN terdapat dua Alat cacah latar rendah (Low Back ground Counter - LBC) TENNELEC yang bagian elektroniknya rusak, sedang bagian mekanik dan detektor masih dapat difungsikan. Alat ini masih sangat diperlukan dalam kegiatan monitoring lingkungan untuk pengukuran cuplikan alpha dan beta. Alat cacah ini menggunakan detektor aliran gas proporsional (proportional gas flow counter) dengan gas P-10. Alat LBC ini aslinya merupakan alat stand alone menggunakan rangkaian mikroprosesor. Untuk memenuhi pertimbangan kemudahan perawatan dan keandalan alat, sistem diubah menjadi sistim PC based dengan tetap mengikuti konsep desain dari alat aslinya. Biasanya sample yang diukur cukup banyak dan dilakukan secara otomatis.

Dalam makalah ini akan dirancang dan dibuat interface pembacaan nomor sample secara otomatis dengan komputer melalui komunikasi serial USB. Pemrograman menggunakan Visual Basic dan diharapkan dapat berfungsi sebagaimana konsep pembacaan nomor sample LBC ini.

\section{METODOLOGI}

Teknologi komputer telah berkembang dengan pesat, dengan hadirnya teknologi interfacing komunikasi serial USB dapat dihubungkan dengan mudah. Pada alat LBC biasanya sample yang diukur cukup banyak dan dilakukan secara otomatis. Setiap sample telah ditandai dengan lobanglobang yang disusun tertentu yang mengindikasikan nomor sample, group, dan send stack reader. Pada bagian mekanik diletakkan beberapa sensor photo transistor sesuai kedudukan sample. Sensor dihubungkan dengan jalur data dan dikirim ke komputer melalui komunikasi serial USB. Kapasitas sample adalah nomor 1 sampai nomor 150 dan kapasitas group dengan nomor 151 sampai nomor 160 yang ditandai dengan group A sampai group J. Dalam refurbishing ini seluruh bagian mekanik dapat dimanfaatkan. Namun bagian elektronik untuk mengontrol seluruh sistem harus diganti dengan trend teknologi terkini yaitu teknologi komunikasi data USB. Penggantian teknologi ini dimaksudkan agar mudah dalam perawatannya, karena komponennya mudah diperoleh dipasaran. Untuk pembacaan nomor sample telah tersedia tempat sample dengan nomor kode tertentu. Kode tersebut dapat dibaca komputer jika melalui sensor nomor sample. 
Selanjutnya hasil sensor dapat diproses melalui rangkaian elektronik yang dibuat sehingga dapat dibaca dan ditampilkan secara on line oleh komputer.

\section{PERANCANGAN}

Untuk dapat merancang rangkaian diperlukan data tempat sample dengan kodenya serta sensor yang digunakan. Tempat sample dengan lobang kode sensor diperlihatkan pada Gambar 1. Lobang tersebut mempunyai bobot nilai tertentu sesuai kedudukan bitnya. Posisi sensor photo transistor pada LBC LB1500 Tennelec diperlihatkan pada Gambar 2. Blok diagram prinsip kerja pembacaan nomor sample diperlihatkan pada Gambar 3.

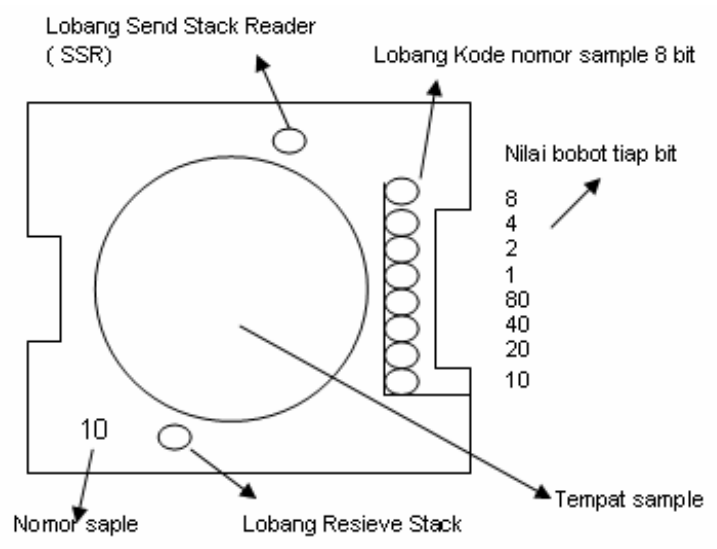

Gambar 1. Tempat Sample dengan Lobang Kode Sensor

Cara kerja gerakan mekanik LBC LB5100 Tennelec sebagai berikut:

1. susun tempat sample sesuai sample yang diinginkan di sebelah kanan.

2. lakukan gerakan panah 1 untuk membaca nonor sample Gambar2.

3. tumpukan akan turun ke bawah, karena sample terbawah bergerak ke kiri.

4. lakukan gerakan panah 2 untuk memasukkan sample tersebut ke tempat detektor.

5. dilakukan pencacahan sample yang dimaksud.

6. keluarkan sample setelah selesai pencacahan dengan gerakan panah 3 .

7. setiap gerakan akan mendorong sample ke arah yang dituju.

8. ulangi langkah 2 untuk mencacah sample berikutnya sampai seluruh sample terbaca oleh komputer.

9. seluruh gerangan dan pencacahan dilakukan secara otomatis dalam refurbishing secara total. Sample yang telah dicacah akan terdorong ke kiri dan menumpuk secara teratur di bagian kiri.

10. jika seluruh sample telah dicounting, maka sensor akan membaca tepat sample END, sehingga seluruh kegiatan telah selesai. 
11. Hasil pencacahan dari beberapa sample tersebut, selanjutnya dapat disimpan dalan bentuk file. Data file kemudian diolah, sehingga didapat informasi monitoring radiasi lingkungan.

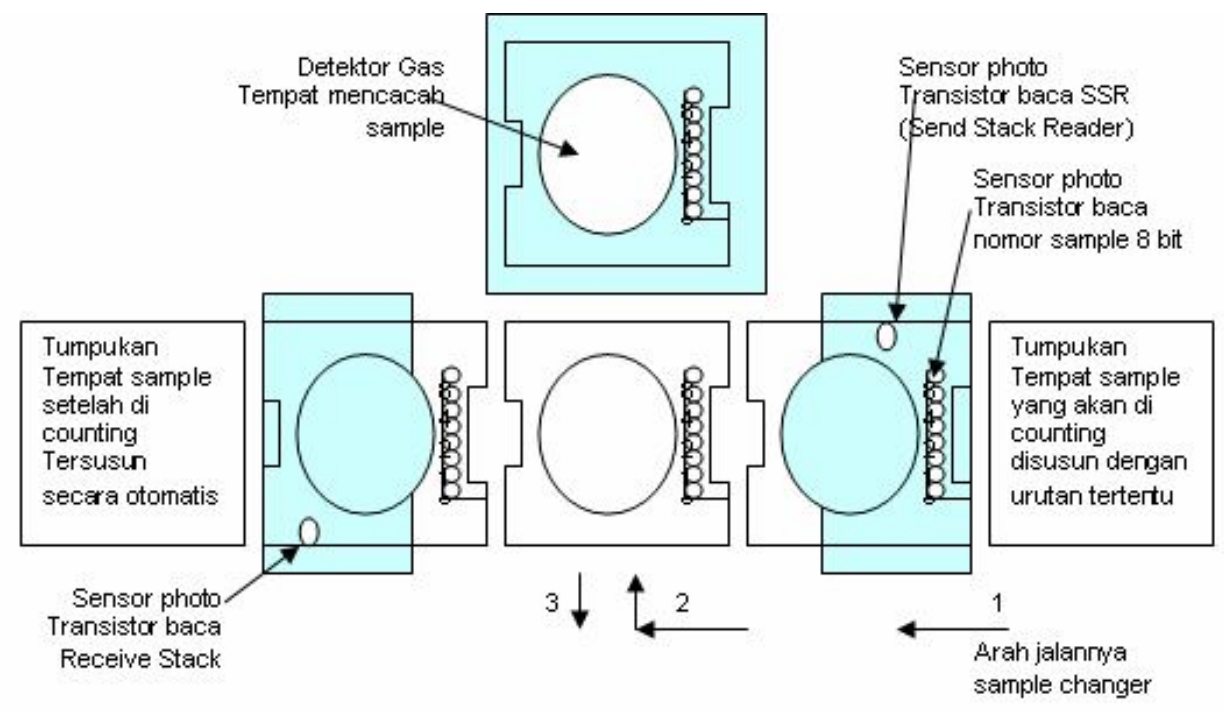

Gambar 2. Posisi sensor photo transistor pada mesin LBC LB1500 Tennelec

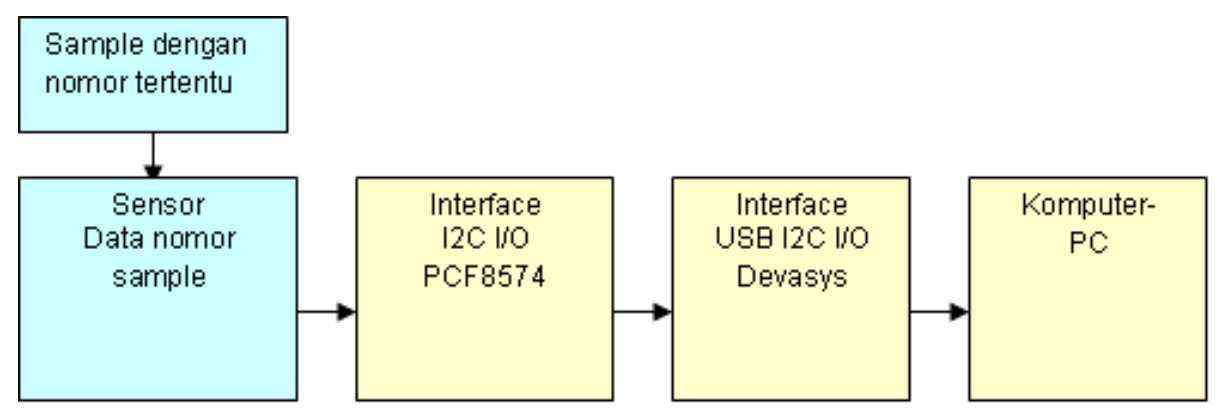

Gambar 3. Blok Diagram Rancangan Pembacaan Nomor Sample

Sensor yang digunakan yaitu photo transistor yang di deret menjadi 8 bit seperti terlihat pada Gambar 4. Dari Gambar 4, setiap bit mempunyai nilai tertentu sehingga menunjukkan nomor sample. Untuk dapat menterjemahkan nomor sample tersebut perlu rumus tertentu dari Tennelec. Nilai bit masingmasing bit 7, 6, 5, 4 nilainya adalah $80,40,20,10$. sedangkan bit 3, 2, 1,0 nilainya adalah $8,4,2,1$. Variasi port data yang berhubungan dengan nomor sample diperlihatkan pada Lampiran 1 Tabel 1. 


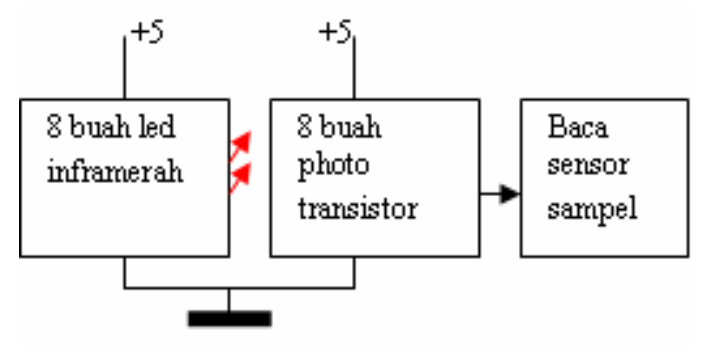

Gambar 4. Rangkaian Sensor Nomor Sample

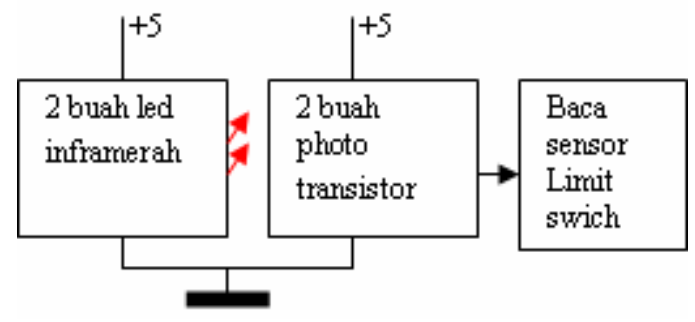

Gambar 5. Rangkaian Sensor Limit Switch

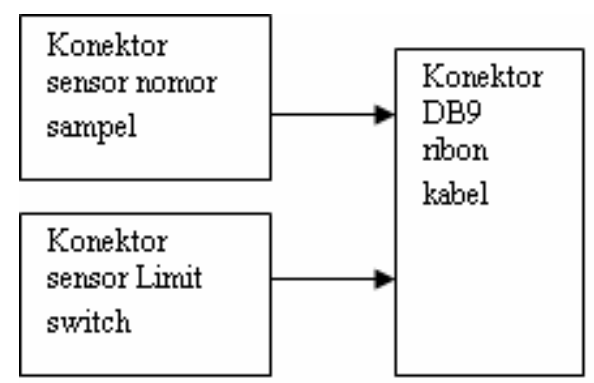

Gambar 6. Konektor Penghubung Sensor Nomor Sample dan Limit Switch

Prinsip kerja photo transistor sebagai sensor diperlihatkan pada Gambar 7. Jika nyala led mengenai basis, maka Opto transistor NPN berfungsi sebagai saklar, sehingga output TTL $=0$. Jika nyala led terhalang sehingga basis trannsistor tidak terkena sinar, maka output TTL $=1$. Prinsip kerja ini digunakan untuk pembacaan nomor sample dan limit switch. 


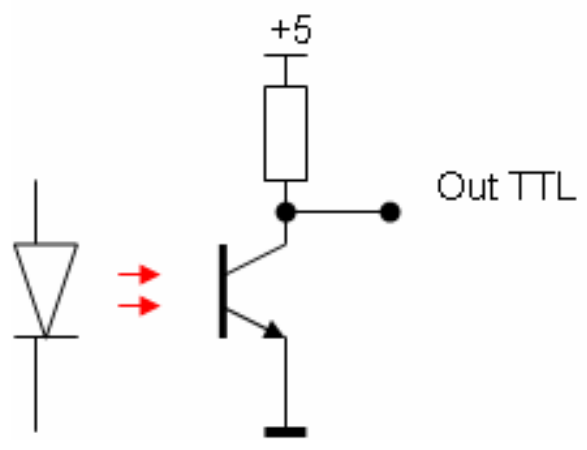

Gambar 7. Prinsip Kerja Photo Transistor

Dengan mempelajari cara kerja sensor dan tata letaknya, dapat dibuat rangkaian skematik interface pembacaan nomor sample diperlihatkan pada Gambar 8.

Pada Gambar 10. Port B ID2 digunakan pengendali gerakan motor Stack dan motor Slide serta pengatur. Interface penggerak motor ini tidak dibahas dalam makalah. Sedangkan jalur I2C akan dihubungkan dengan rangkaian pembacaan nomor sample dan limit switch.

Dalam pengoperasiannya perlu instalasi dimana, output sensor DB9 (Gambar 6. ) dihubungkan dengan kabel ribon ke output rangkaian baca sensor (Gambar 9.) Selanjutnya Terminal I2C rangkaian baca sensor (Gambar 10) dihubungkan dengan terminal I2C interface devasys, sedangkan port I/O IDC J1 dihubungkan dengan parallel Port IDC devasys. Input interface devasys dihubungkan dengan kabel serial USB ke komputer. Instalasi ini sesuai dengan blok diagram rancangan pembacaan nomor sample pada alat LBC LB5100 Tennelec. Selanjutnya dilakukan uji fungsi sesuai cara kerja LBC LB5100 seri II Tennelec.

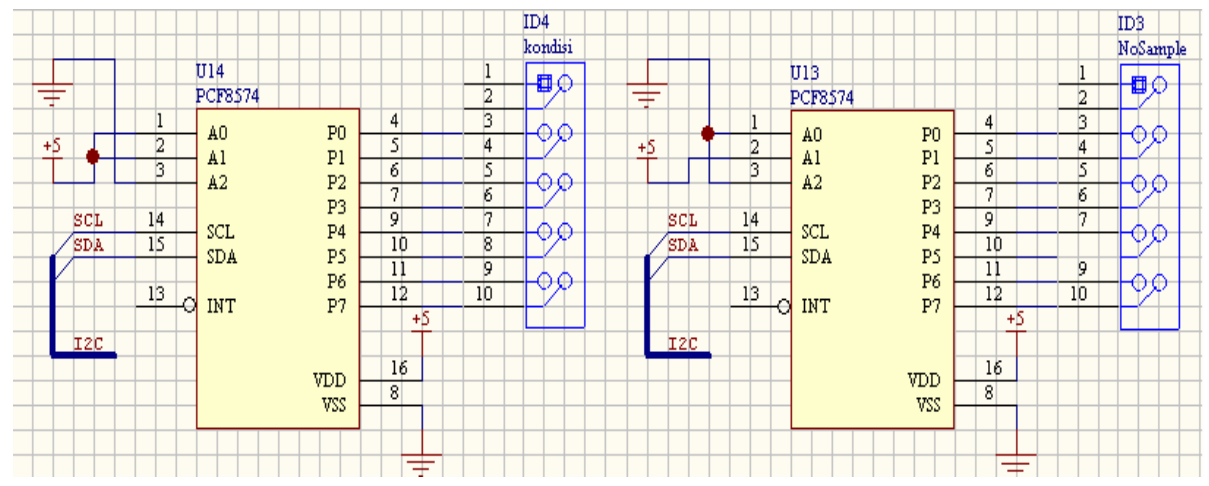

Gambar 8. Rangkaian Modul Pembacaan Nomor Sample \& Limit Switch 


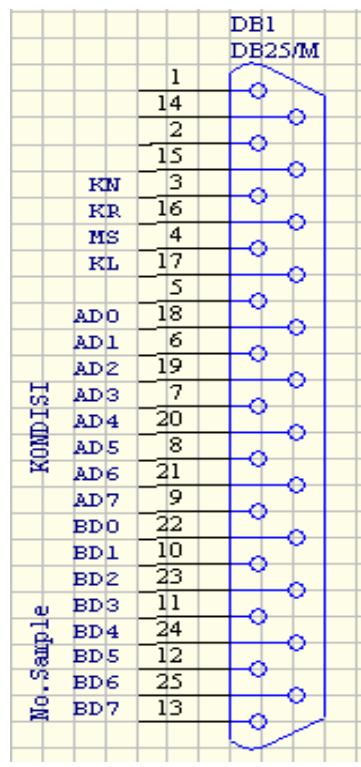

Gambar 9. DB9 Input Konektor Sensor

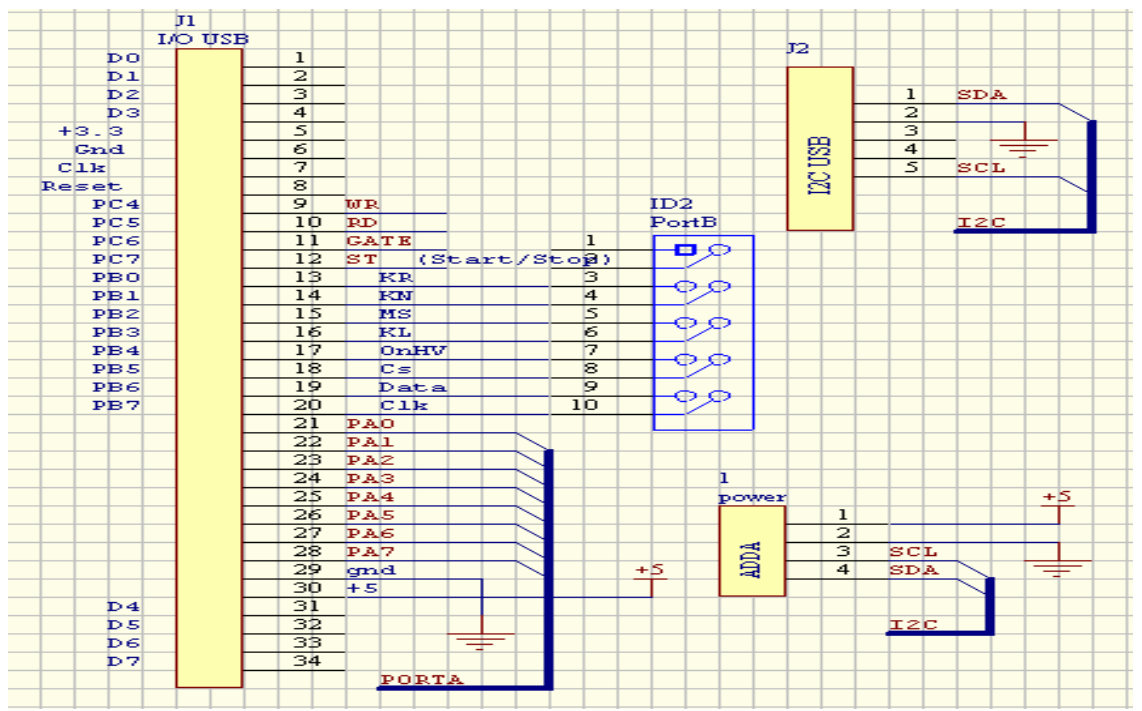

Gambar 10. Koneksi Modul Pembacaan Nomor Sample dan Kondisi Limit Switch ke Modul Interface USB 


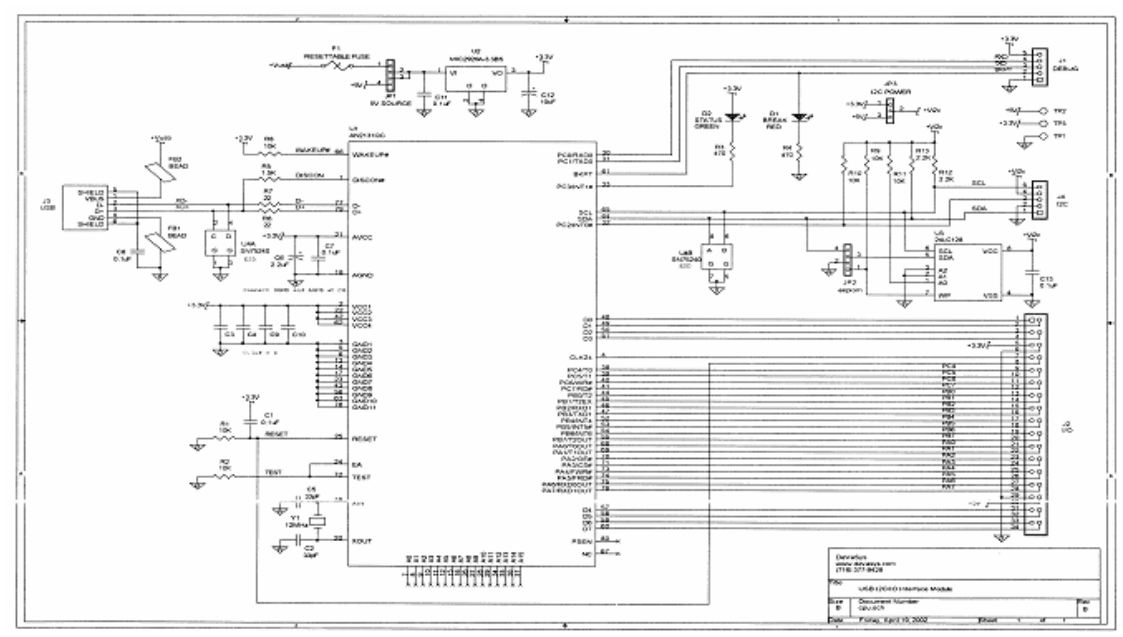

Gambar 11. Interface USB dari Devasys I2C I/O

\section{HASIL DAN PEMBAHASAN}

Data hasil pengujian diperlihatkan pada Lampiran. Dari uraian diatas dapat dianalisis sebagai berikut:

1. Nomor sample dan limit switch dibaca dengan sensor photo transistor yang disusun sedemikian rupa, sehingga membentuk data 8 bit nomor sample dan data 8 bit limit switch.

2. Pembacaan dengan komponen 8 bit I/O parallel to I2C dari PCF8574.

3. Pembacaan dilakukan melalui trend teknologi komunikasi data serial USB.

4. Antar muka ( interface) yang digunakan adalah Devasis I2C I/O yang memiliki 20 pin parallel port dan port I2C I/O. Port_A 8 bit direncanakan untuk jalur data paralel I/O. Port_B 8 bit untuk kontrol penggerak motor dan pengatur jendela pengukuran radiasi alfa dan beta.

5. Agar kode nomor sample dapat dibaca dengan benar sesuai kaidah yang diinginkan, maka sensor 8 bit dibaca dengan kode hexsa. Selanjutnya kode hexsa dipisah MSB dan LSB nya. Setelah dipisah, MSB hexsa diubah menjadi MSB desimal., sedangkan LSB hexsa diubah menjadi LSB desimal.

6. Pembacaan nomor sample dilakukan dengan rumus :

$$
\text { NOMOR SAMPLE }=(10 *(\text { MSB DESIMAL })+(\text { LSB DESIMAL }))
$$

7. Blok diagram aliar pembacaan nomor sampel diperlihatkan pada Gambar 12. 


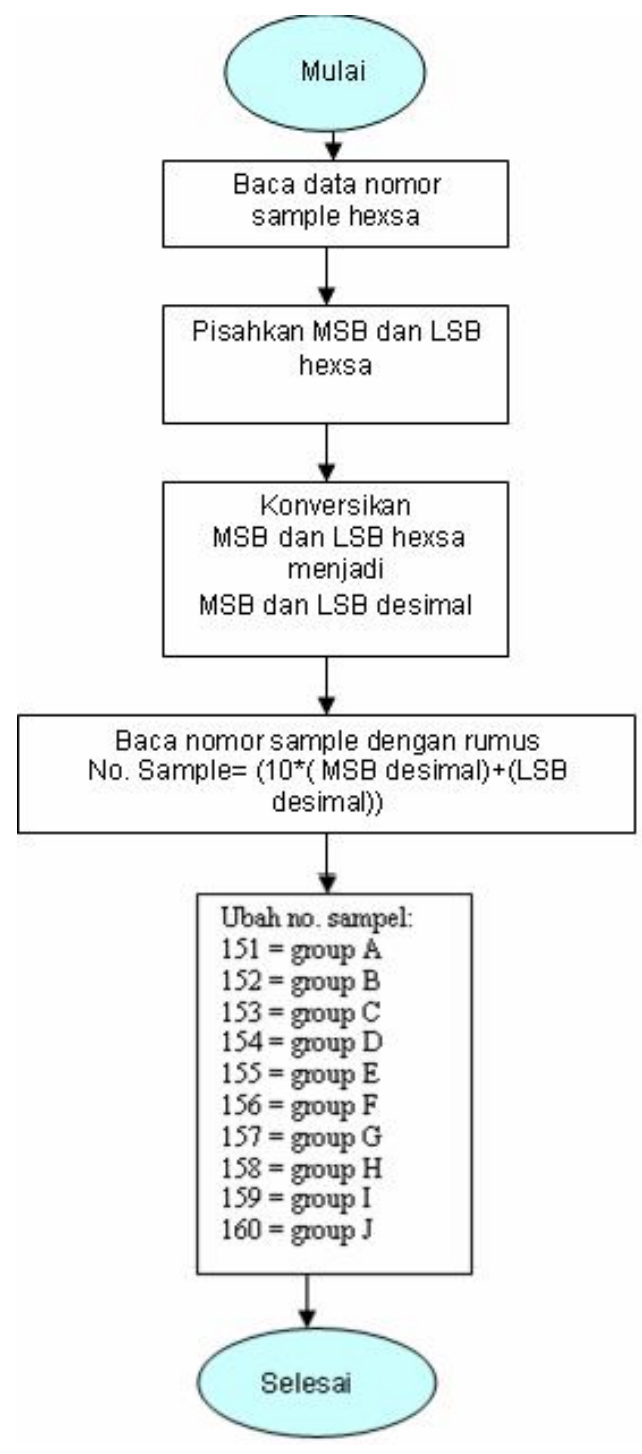

Gambar 12. Blok Diagram Alir Pembacaan Nomor Sampel

Blok diagram rancangan pembacaan nomor sample diperlihatkan pada Gambar 2. Dari Tabel 2 tersebut diperoleh hasil pembacaan nomor sample telah sesuai dengan yang diharapkan.

\section{KESIMPULAN}

Telah dirancang dan dibuat interface pembacaan nomor sample secara otomatis dengan komputer melalui komunikasi serial USB dalam rangka refurbishing alat LBC TENNELEC type LB1500. Dari hasil pengujian 
menunjukkan bahwa alat telah dapat membaca nomor sample sesuai dengan yang diharapkan

\section{DAFTAR PUSTAKA}

1. MANUAL, 2001, "User Manual Eclipse LB S550", Tennelec, Canberra Industries USA.

2. TENNELEC, 1985, "Instruction Manual LB 5100 series II Operating Instruction Rev.1.0", Tennelec, Canberra Industries USA.

3. TENNELEC, "Introduction to Tennelec Low-Background Counting systems", Canberra Industries USA

\section{UCAPAN TERIMA KASIH}

Terima kasih kami ucapkan kepada Bp. Drs. Rukmono Pribadi atas diskusi dan pelaksanaan refurbishing perangkat LBC ini. Kepada Bp. Agus Gindu serta Rekan-rekan Pusat Teknologi Keselamatan dan Metrologi Radiasi yang memberi fasilitas alat tersebut. 